\title{
Donuk omuzda artroskopik kapsüler gevşetme ve klinik sonuçları
}

\author{
Arthroscopic capsular release for frozen shoulder and clinical outcomes
}

\author{
Ata Can Atalar ${ }^{1}$, Onur Tunalı ${ }^{2}$ \\ ${ }^{1}$ Acıbadem Üniversitesi Tıp Fakültesi, Ortopedi ve Travmatoloji Ana Bilim Dalı, İstanbul \\ ${ }^{2}$ Acıbadem Maslak Hastanesi, Ortopedi ve Travmatoloji Kliniği, İstanbul
}

\begin{abstract}
Artroskopik kapsüler gevşetme, konservatif tedavi yöntemleriyle tedavi edilemeyen donuk omuz hastalarında başlıca cerrahi tedavi seçeneğidir. Eşlik edebilen omuz patolojilerini de ortaya koyması ve aynı seansta tedavi edebilmesi, kapsülün kontrollü bir şekilde $360^{\circ}$ gevşetilebilmesi ve erken rehabilitasyona başlanabilmesi en önemli avantajlarıdır. Kapsüler gevşetme sırasında dikkat edilmesi gereken en önemli yapı aksiller sinirdir. Kapsül glenoide yakın kısımdan gevşetilmeli ve saat 5 ila 7 arasında aksiller sinirin yakın komşuluğu unutulmamalıdır. Ameliyat sonrası ağrı kontrolü ve erken hızlı rehabilitasyona başlanabilmesi için interskalen kateter yerleştirilmesi önemlidir. Artroskopik kapsüler gevşetme, erken rehabilitasyonla birlikte karşı omuz ile benzer fonksiyonel sonuçlar elde edilebilen, komplikasyon oranı düşük, başarılı bir yöntemdir.
\end{abstract}

Anahtar sözcükler: donuk omuz; kapsüler gevşetme; artroskopi; aksiller sinir

$\mathrm{D}$ onuk omuz veya adeziv kapsülit ağırlıklı olarak konservatif yöntemlerle tedavi edilir. Ancak konservatif yöntemler ile tedavi edilemeyen donuk omuz hastalarında cerrahi tedavi uygulanmaktadır. Cerrahi tedavi seçenekleri; anestezi altında manipülasyon, açık kapsüler gevşetme ve artroskopik kapsüler gevşetmedir. ${ }^{[1]}$ Anestezi altında manipülasyon ile başarılı sonuçlar ${ }^{[2]}$ bildirilmekle beraber iyatrojenik yaralanma (süperior labrum yırtığı, subskapularis yırtığı, anterior labrum yırtığı, kondral hasar, kırık) riskinin olması ve kapsülün kontrolsüz olarak yırtılması gibi dezavantajları bulunmaktadır. ${ }^{[3,4]}$ Açık kapsüler gevşetme daha çok travma sonrası (posttravmatik) veya cerrahi geçirmiş hastalarda uygulanmakla birlikte, subskapularisin kaldırılmasını gerektirmesi, posterior
Arthroscopic capsular release is the main surgical treatment method for the patients with frozen shoulder who can not be treated with conservative methods. Detection and simultaneous treatment of concomitant shoulder pathologies, $360^{\circ}$ controlled release of the capsule and letting early rehabilitation are the advantages of arthroscopic release. The most important structure to be considered during capsular release is the axillary nerve. The capsule should be released from the part close to the glenoid and the close relation of the axillary nerve to the capsule should not be forgotten between 5 and 7 o'clock positions. Interscalene catheter placement is important for postoperative pain control and early rapid rehabilitation. Arthroscopic capsular release with early rehabilitation is a successful method with a low complication rate that can achieve similar functional results with the contralateral shoulder.

Key words: frozen shoulder; capsular release; arthroscopy; axillary nerve

kapsülün gevşetilememesi ve erken rehabilitasyona başlanamaması gibi negatif yönleri bulunmaktadır. Artroskopik kapsüler gevşetme ilk olarak Conti tarafından 1979 yılında tarif edilmiştir. ${ }^{[5]}$ Zaman içinde gelişen artroskopik teknikler sonrasında artroskopik kapsüler gevşetme giderek daha sık uygulanmaya başlamış ve en önemli cerrahi yöntem halini almıştır. Kapsülün kontrollü bir şekilde $360^{\circ}$ gevşetilebilmesi, rotator intervalin ve subskapularisin gevşetilebilmesi, ek eklem içi patolojilerin [superior labral anterior posterior (SLAP) lezyonu, biseps lezyonu, supraspinatus yırtığı gibi] ortaya konabilmesi ve tedavi edilebilmesi, daha erken rehabilitasyona izin vermesi ve manipülasyona bağlı iyatrojenik yaralanmaların görülmemesi artroskopik kapsüler gevşetmenin avantajlarıdır.

illetişim / Contact: Prof. Dr. Ata Can Atalar •E-posta / E-mail: atacan.atalar@acibadem.edu.tr

ORCID iD: Ata Can Atalar, 0000-0002-5708-9259 • Onur Tunalı, 0000-0002-7808-9426

Geliş / Received: 15 Ocak 2022 • Kabul / Accepted: 10 Şubat 2022 


\section{ANESTEZI VE HASTA POZISYONU}

Artroskopik gevşetme genel anestezi, interskalen blok veya iki yöntemin kombinasyonu ile yapılabilir. Interskalen kateter takılması ameliyat sonrası ağrı kontrolünü ve erken hareket başlanmasını sağlar. Kliniğimizde donuk omuz tanısıyla gevşetme yapılan hastalara mutlaka skalen kateter takılıp ameliyat sonrası aynı gün pasif hareketlere başlanmakta ve hasta üç gün süreyle kateter yardımıyla ağrı kontrolü sağlanarak fizik tedavi görmektedir.

Artroskopik gevşetme şezlong pozisyonu veya lateral dekübit pozisyonunda uygulanabilir. Şezlong pozisyonunun avantajları; manipülasyonun kolay olması, omuz hareketlerinin açılıp açılmadığının kontrol edilebilmesi, pozisyon için ek bir traksiyon aletine ihtiyaç olmaması, pozisyonun sık kullanılması ve cerrahların alışık olmasıdır. Lateral dekübit pozisyonun avantajları ise inferior kapsüle daha rahat ulaşılması, manipülasyon gereksiniminin az olması, hipotansiyon ve beyin perfüzyonunun azalma riskinin olmamasıdır. 2019 yılında yapılan derlemede fonksiyonel sonuçlar açısından her iki pozisyon arasında fark bulunmamıştır. Şezlong pozisyonunda yapılan gevşetme sonrası daha fazla oranda manipülasyon yapıldığı bildirilmiştir (\%91/\%63). ${ }^{[6]}$ Yazarlar olarak şezlong pozisyonunu rutin olarak kullanmaktayız.

\section{CERRAHI TEKNIK}

Hasta anestezi altında şezlong pozisyonunda hazırlandıktan sonra artroskopiye başlamadan önce hastanın omuz hareketleri değerlendirilir ve kayıt altına alınır. Anatomik nirengi noktaları ve portal yerleri kalemle çizilir. Sonrasında standart posterior portalden glenohumeral ekleme girilir. Bu sırada bir asistan tarafından kola manivela yapılarak eklem aralığı genişletilmeye çalışılır. Donuk omuz hastalarında eklem daraldığı ve kapsül kalınlaştığı için bazı hastalarda ekleme girmek zor olabilir. Posterior portalde ekleme girilemediği durumda anteriordan rotator intervalden ekleme girilebilir.

Posterior portalden glenohumeral ekleme girildiğinde öncelikle tanısal artroskopi yapılır. Anterior kapsülün kalınlaşmış ve ödemli (inflame) olduğu görülür (Şekil 1a). Rotator intervalin fibrotik doku ile dolu olduğu görülür. Biseps, labrum, supraspinatus ve infraspinatusun eklem yüzü değerlendirilir. Korakoidin hemen lateralinden dıştan içe teknik ile spinal iğne yardımı ile subskapularisin üzerinden anterior portal açılır ve kanül yerleştirilir. Biseps uzun başının anteriorundan itibaren rotator interval ve subkorakoid alandaki dokular radyofrekans ve shaver ile temizlenir. Rotator interval açılır. Glenoid labrumun 2-5 mm lateralinden anterior kapsül inferiora doğru radyofrekans ile açılır. ${ }^{[7,8]}$ Kapsülün kesilmesi sırasında kıkırdak ve labrumu korumak ve daha kontrollü bir kesi yapmak için çengel uçlu radyofrekans cihazı kullanılabilir. Bazı yazarlar radyofrekans yerine artroskopik punch kullanılmasını önermiştir ${ }^{[9]}$ İnferior kapsüle doğru ilerlerken aksiller sinirin yakın komşuluğundan dolayı çok dikkatli olunmalıdır. Yapılan kadavra çalışmalarında aksiller sinirin glenohumeral eklem kapsülüne en yakın olduğu konumun saat 5 ila 7 arası olduğu ve aksiller sinirin kapsülün humerusa yapışma yerine glenoid yapışma yerine göre daha yakın olduğu gösterilmiştir. ${ }^{[10,11]}$ Bundan dolayı kapsül gevşetilirken labrumun hemen lateralinden glenoide yakın kısmından gevşetilmelidir. Kol abduksiyon ve dış rotasyona alındığında eklem kapsülünün gerildiği ve aksiller sinir ile kapsül arasındaki mesafenin arttığı gösterilmiştir. Bu yüzden antero-inferior kapsül gevşetilirken kolun abduksiyon ve dış rotasyona alınması aksiller sinirin korunmasına yardımcı olur. Kapsül inferiorda anterior portalden ulaşılabilen yere kadar gevşetilir. Kapsülün tam olarak gevşetildiği subskapularis kas liflerinin görülmesi ile anlaşılır (Şekil 1b).

Subskapularis tendonun etrafındaki yapışıklıklar açılarak tendon iyice serbestleştirilir. Dış rotasyonun tam

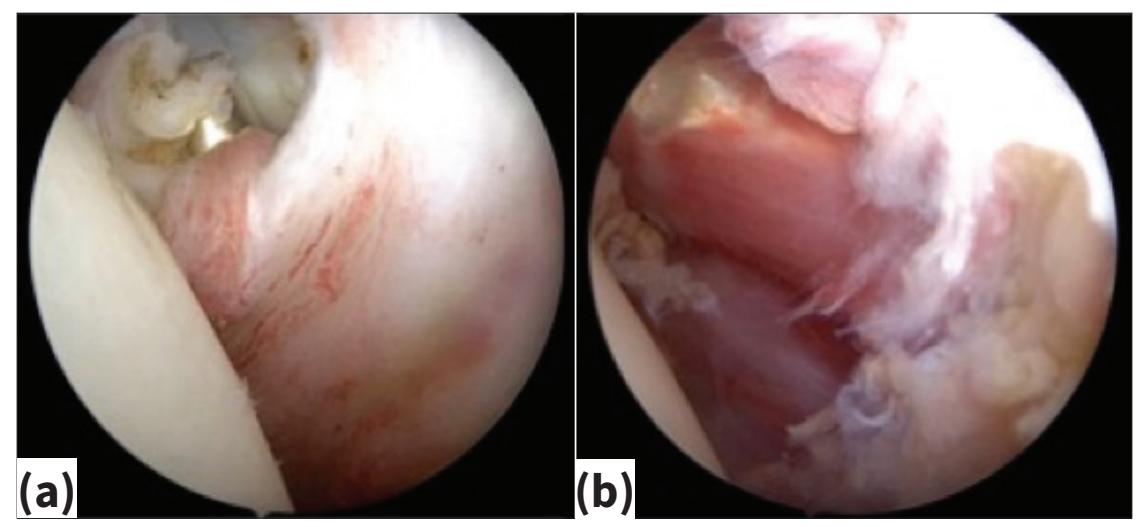

Şekil 1.a,b. Kalınlaşmış ve inflame kapsülün görünümü (a). Artroskopik gevşetme sonrası subskapularis kas liflerinin görünmesi (b). 
olarak sağlanamadığı durumlarda subskapularis tendonun üst $1 / 4^{\prime}$ lük kısmının eklem içi (intraartiküler) olarak gevşetilmesi önerilmiştir. ${ }^{[7,12]}$ Liem ve ark. yaptıkları çalışmada subskapularisin intraartiküler olarak gevşetilmesinin subskapularis kuvvetinde herhangi bir azalmaya yol açmadığını bildirmiştir. ${ }^{[13]}$ Yazarlar olarak subskapularis çevresindeki yapışıklıkların açılıp gevşetilmesinin yeterli olduğunu ve subskapularis tendonunun gevşetilmesine gerek olmadığını düşünmekteyiz.

2001 yılına kadar bildirilen çalışmalarda donuk omuzun artroskopik tedavisinde yalnızca anterior ve antero-inferior kapsülün gevşetilmesi yeterli görülmüş posterior kapsül gevşetilmesi önerilmemiştir. ${ }^{[12,14-16]}$ Jerosch özellikle iç rotasyonun tekrar kazanılması için posterior kapsülün de gevşetilmesi gerektiğini belirtmiş ve cerrahi tekniklerini ve sonuçlarını bildirmiştir. ${ }^{[7]}$ Takip eden yıllarda $360^{\circ}$ kapsüler gevşetme popülerleşmiş ve daha sık uygulanır hale gelmiştir. Kim ve ark. yaptıkları prospektif randomize kontrollü çalışmada posterior kapsül gevşetilen hastalarla gevşetilmeyenler arasında fonksiyonel sonuçlar, ağrı ve hareket açıklığı arasında istatistiksel olarak anlamlı bir fark olmadığını bildirmiştir. ${ }^{[17]}$

Antero-inferior kapsül gevşetildikten sonra posterior kapsülün gevşetilmesine geçilir. Rod yardımıyla skop anterior portale alınarak posterior kapsül görüntülenir. Posterior portalden posterior kapsül süperiordan inferiora doğru radyofrekans ile kesilir. Posterior kapsülün gevşetilmesi için iğne yardımıyla postero-inferiordan ek bir portal de açılabilir. ${ }^{[8]}$

Kapsül $360^{\circ}$ derece olacak şekilde tamamen gevşetilmeye çalışılır. Aksiller sinire zarar vermemek için ve inferior kapsüle ulaşmak her zaman mümkün olmadığından kapsülün inferior kısmı gevşetilmeyebilir. Kalan kapsül kısmının kola manipülasyon yapılarak açılması sağlanır ve sonrasında artroskopik olarak kapsülün $360^{\circ}$ olarak açıldığı kontrol edilir (Şekil 2). Manipülasyona abduksiyon ile başlanır. Öne fleksiyon ve ekstansiyon ile devam edilip dış ve iç rotasyon ile manipülasyon tamamlanır. ${ }^{[8]}$ Manipülasyon sırasında bir asistan tarafından skapula sabitlenmelidir.

Rutin olarak subakromial dekompresyon veya akromioplasti yapılmaz. Eşlik eden akromial patoloji (spur, sıkışma sendromu) veya rotator manşet yırtığı varsa gerekli işlemler yapılır. Eşlik eden rotator manşet yırtığı varsa kapsüler gevşetme sonrasında uygun teknikle rotator manşet tamiri yapılır.

Artroskopik kapsüler gevşetme tamamlandıktan sonra portaller sütüre edilir. Pansuman yapılır ve kol askısı takılır. Aynı gün kateter yardımıyla fizyoterapist eşliğinde pasif öne fleksiyon, dış rotasyon ve abduksiyon hareketleri

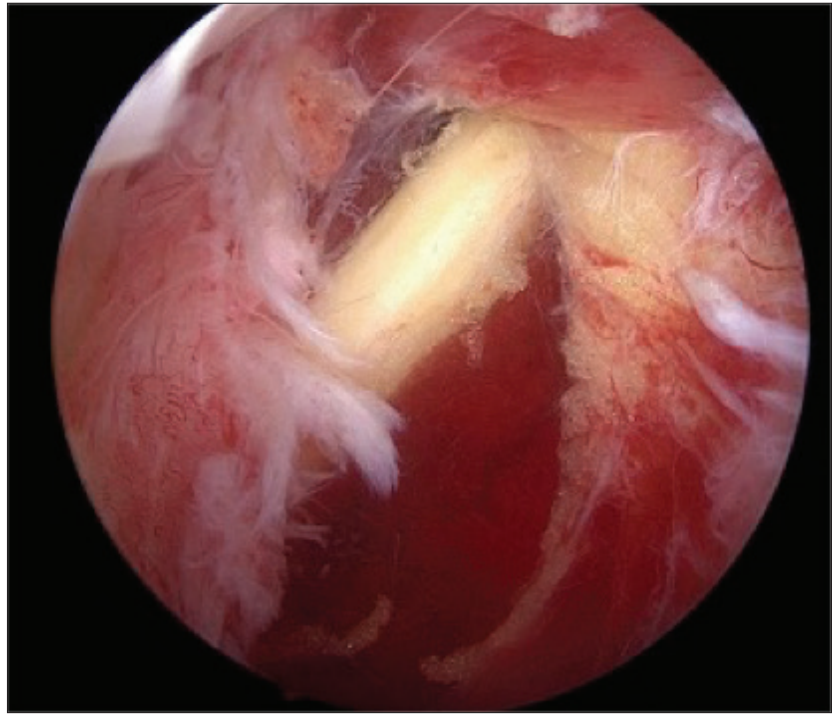

Şekil 2. İnferior kapsülün gevşetilmesi sonrasında aksiller sinirin görünümü.

başlanır. Kol askısı kısa süreli olarak konfor için kullanılır. Hastanın kolunu kullanması teşvik edilir. Taburculuk sonrası evde egzersiz programı ve ayaktan fizik tedavi ile hareket açıklığının korunması ve artırılması hedeflenir.

\section{KLINIK SONUÇLAR}

Artroskopik kapsüler gevşetme ile ilgili literatür incelendiğinde başarılı fonksiyonel sonuç ve düşük komplikasyon bildiren çok sayıda yayın bulunmaktadır. $360^{\circ}$ kapsüler gevşetmeyi tarifleyen Jerosch 28 hastalık serisinde ameliyat sonrası hareket açıklığının anlamlı derece artığını ve neredeyse karşı omuz ile benzer derecelere geldiğini belirtmiştir. Aynı çalışmada anestezi altında manipülasyon yapılan hastalara göre, artroskopik gevşetme yapılan hastaların ameliyat sonrası dönemde daha az ağrıları oldukları bildirilmiştir. ${ }^{[7]}$

Lievre ve ark. 2012 yılında artroskopik global kapsüler gevşetme yapılan 49 omzun ortalama yedi yıllık takip sonuçlarını bildirmiştir. Yedi yıl sonunda hastaların hareket açıklıklarının karşı omuz ile benzer olduğu ve fonksiyonel olarak hastaların eski seviyelerine döndükleri ve hiçbir komplikasyonla karşılaşılmadığı bildirilmiştir. ${ }^{[18]}$

Jerosch ve ark. 2013 yılında primer ve sekonder donuk omuz olan artroskopik kapsüler gevşetme yapılan 167 hastanın orta dönem sonuçlarını bildirmiştir. ${ }^{[19]}$ Her iki grupta da fonksiyonel ve ağrı skorlarının anlamlı derecede düzeldiğini, primer donuk omuz grubunda Constant skorunun 85 'e, sekonder grupta ise 74 'e yükseldiğini bildirmişlerdir. Bu çalışmada komplikasyon olarak bir hastada enfeksiyon ve beş hastada $(\% 2,9)$ nüks (rekürrens) saptanmıştır. 
Barnes ve ark. 2016 yılında artroskopik gevşetme uyguladıkları 133 hastanın kısa dönem sonuçlarını bildirmiştir. Hastaların ağrılarının ve hareket açıklığının ameliyat sonrası birinci haftada anlamlı derecede düzeldiğini, 24 haftaya kadar giderek ilerleme kaydettiğini ortaya koymuşlar ve herhangi bir komplikasyonla karşılaşmamışlardır. ${ }^{[20]}$

Kanbe 2018 yılında 255 hastanın beş yıllık takip sonuçlarını bildirmiştir. Diyabeti olan hastalarda biseps uzun başı ile korakohumeral ligaman arasındaki adezyonun daha fazla olduğunu ve bunun fonksiyonel skorları olumsuz yönde etkilediğini bildirmiştir. ${ }^{[21]}$

Elhassan ve ark. yaptıkları çalışmada etiyolojinin fonksiyonel sonuçları üzerine etkisini araştırmışlar. İdiopatik ve post-travmatik donuk omuz vakalarının cerrahi sonrası görülen donuk omuz vakalarına göre daha iyi fonksiyonel sonuçları olduğunu bildirmişlerdir. ${ }^{[22]}$ Diyabetin fonksiyonel sonuçlar üzerine etkisine yönelik yapılan çalışmalarda, diyabeti olan hastaların özellikle ameliyat sonrası birinci yıla kadar diyabeti olmayanlara göre daha kötü sonuçları olduğu, ameliyat sonrası ikinci yılda ise diyabeti olmayanlara yakın sonuçlara erişebildiği bildirilmiştir. Diyabeti olan hastalarda iyileşmenin daha yavaş olduğu ancak her iki grupta da fonksiyonel skorların ameliyat öncesi değerlere göre anlamlı şekilde düzeldiği gösterilmiştir. ${ }^{[23,24]}$ Rizvi ve ark. semptomların başlangıcından itibaren geçen sürenin fonksiyonel sonuçlara etkisini araştırmışlardır. Bu çalışmada 10 aydan kısa süreli şikayeti olanlarda ameliyat öncesi hareket açıklığının 10 aydan uzun süre şikâyeti olanlara göre daha kısıtlı olduğu, ameliyat sonrası dönemde ise iç rotasyon dışında hareket açıklığı sonuçlarının benzer olduğu bildirilmiştir. Iç rotasyon derecesindeki iyileşme ise semptom süresi 10 aydan kısa olan grupta daha iyi bulunmuş ve ameliyatın geciktirilmesine gerek olmadığı belirtilmiştir. ${ }^{[25]}$

Yıldız ve ark. yaptıkları çalışmada eşlik eden omuz patolojilerin fonksiyonel sonuçlar üzerine olan etkisini araştırmış ve SLAP, sıkışma sendromu, akromiyoklaviküler artroz ve parsiyel supraspinatus yırtığı gibi eşlik eden patolojilerin fonksiyonel sonuçları etkilemediğini bildirmiştir. ${ }^{[26]} 2019$ yılında 463 donuk omuz hastasını içeren bir derlemede ise diyabetik hastalarda daha fazla rezidüel ağrı olduğu ve fonksiyonların daha kötü olduğu ortaya konmuştur. Aynı çalışmada cerrahi sonrası görülen donuk omuz vakalarında revizyon gereksiniminin idiopatik vakalara göre daha fazla olduğu bildirilmiştir $(\% 8,1-2,4)$. ${ }^{[27]}$

Grant ve ark.'nın anestezi altında manipülasyon ile artroskopik kapsüler gevşetmeyi karşılaştırdığı sistematik derlemede fonksiyonel skorlar, hareket açıklığı ve komplikasyon oranları değerlendirilmiştir. ${ }^{[28]}$ Abduksiyon ve kol yandayken dış rotasyon hareket açıklığı ve Constant skorları kapsüler gevşetme grubunda daha iyi bulunmuş, öne fleksiyon değerleri ise benzer bulunmuştur. Komplikasyonlar incelendiğinde her iki grup arasında bir fark bulunamamıştır. Gallacher ve ark. yaptıkları randomize kontrollü çalışmada hidrodilatasyon ile kapsüler gevşetmeyi karşılaştırmıştır. Ameliyat sonrası altıncı ay kontrollerinde Oxford omuz skoru, öne fleksiyon ve dış rotasyon hareket açıklığı kapsüler gevşetme yapılan grupta istatistiksel olarak anlamlı derecede daha iyi bulunmuştur. ${ }^{[29]}$

Artroskopik kapsüler gevşetme sırasında en sık karşılaşılabilen komplikasyon yeterli gevşetmenin yapılamaması veya tekrar sertlik oluşmasıdır. Nadir görülen komplikasyonlar olarak aksiller sinir yaralanması, omuz dislokasyonu, anterior instabilite ve kondroliz bildirilmiştir. ${ }^{[28]}$

\section{SONUÇ}

Artroskopik kapsüler gevşetme konservatif yöntemlere yanıt vermeyen donuk omuz olgularında doğru teknikle uygulandığında güvenli ve başarılı bir yöntem olarak karşımıza çıkmaktadır. Yöntemin başarılı olması için interskalen kateter ile ağrı kontrolü ve düzgün rehabilitasyon ile desteklenmesi gereklidir.

\section{KAYNAKLAR}

1. Le HV, Lee SJ, Nazarian A, Rodriguez EK. Adhesive capsulitis of the shoulder: review of pathophysiology and current clinical treatments. Shoulder Elbow 2017;9:75-84. Crossref

2. Farrell CM, Sperling JW, Cofield RH. Manipulation for frozen shoulder: long-term results. J Shoulder Elbow Surg 2005;14:480-4. Crossref

3. Loew M, Heichel TO, Lehner B. Intraarticular lesions in primary frozen shoulder after manipulation under general anesthesia. J Shoulder Elbow Surg 2005;14:16-21. Crossref

4. Magnussen RA, Taylor DC. Glenoid fracture during manipulation under anesthesia for adhesive capsulitis: a case report. J Shoulder Elbow Surg 2011;20:e23-6. Crossref

5. Conti V. Arthroscopy in rehabilitation. Orthop Clin North Am 1979;10:709-11. Crossref

6. Houck DA, Belk JW, Vidal AF, McCarty EC, Bravman JT, Seidl AJ, et al. Outcomes of arthroscopic capsular release in the beach-chair versus lateral decubitus position: a systematic review. Orthop J Sports Med 2019;7:2325967119888173. Crossref

7. Jerosch J. 360 degrees arthroscopic capsular release in patients with adhesive capsulitis of the glenohumeral joint-indication, surgical technique, results. Knee Surg Sports Traumatol Arthrosc 2001;9:178-86. Crossref 
8. Beimers L, Murrell GAC. Arthroscopic capsular release for idiopathic adhesive capsulitis. JBJS Essent Surg Tech 2014;3:e2. crossref

9. Cutbush K, Italia K, Narasimhan R, Gupta A. Frozen Shoulder 360 degrees release. Arthrosc Tech 2021;10:e963-e7. Crossref

10. Uno A, Bain GI, Mehta JA. Arthroscopic relationship of the axillary nerve to the shoulder joint capsule: an anatomic study. J Shoulder Elbow Surg 1999;8:226-30. Crossref

11. Jerosch J, Filler TJ, Peuker ET. Which joint position puts the axillary nerve at lowest risk when performing arthroscopic capsular release in patients with adhesive capsulitis of the shoulder? Knee Surg Sports Traumatol Arthrosc 2002;10:1269. Crossref

12. Pearsall AWT, Holovacs TF, Speer KP. The intra-articular component of the subscapularis tendon: anatomic and histological correlation in reference to surgical release in patients with frozen-shoulder syndrome. Arthroscopy 2000;16:236-42. Crossref

13. Liem D, Meier F, Thorwesten L, Marquardt B, Steinbeck J, Poetzl W. The influence of arthroscopic subscapularis tendon and capsule release on internal rotation strength in treatment of frozen shoulder. Am J Sports Med 2008;36:921-6. Crossref

14. Ogilvie Harris DJ, Wiley AM Arthroscopic surgery of the shoulder. A general appraisal. J Bone Joint Surg Br 1986;68:201-7. Crossref

15. Beaufils P, Prevot N, Boyer T, Allard M, Dorfmann H, Frank A, et al. Arthroscopic release of the glenohumeral joint in shoulder stiffness: a review of 26 cases. French Society for Arthroscopy. Arthroscopy 1999;15:49-55. Crossref

16. Ogilvie Harris DJ, Myerthall S. The diabetic frozen shoulder: arthroscopic release. Arthroscopy 1997;13:1-8. Crossref

17. Kim YS, Lee HJ, Park IJ. Clinical outcomes do not support arthroscopic posterior capsular release in addition to anterior release for shoulder stiffness: a randomized controlled study. Am J Sports Med 2014;42:1143-9. Crossref

18. Le Lievre HM, Murrell GA. Long-term outcomes after arthroscopic capsular release for idiopathic adhesive capsulitis. J Bone Joint Surg Am 2012;94:1208-16. Crossref

19. Jerosch J, Nasef NM, Peters O, Mansour AM. Mid-term results following arthroscopic capsular release in patients with primary and secondary adhesive shoulder capsulitis. Knee Surg Sports Traumatol Arthrosc 2013;21:1195-202. Crossref
20. Barnes CP, Lam PH, Murrell GA. Short-term outcomes after arthroscopic capsular release for adhesive capsulitis. J Shoulder Elbow Surg 2016;25:e256-64. Crossref

21. Kanbe K. Clinical outcome of arthroscopic capsular release for frozen shoulder: essential technical points in 255 patients. J Orthop Surg Res 2018;13:56. Crossref

22. Elhassan B, Özbaydar M, Massimini D, Higgins L, Warner JJ. Arthroscopic capsular release for refractory shoulder stiffness: a critical analysis of effectiveness in specific etiologies. J Shoulder Elbow Surg 2010;19:580-7. Crossref

23. Mehta SS, Singh HP, Pandey R. Comparative outcome of arthroscopic release for frozen shoulder in patients with and without diabetes. Bone Joint J 2014;96-B:1355-8. Crossref

24. Cho CH, Kim DH, Lee YK. Serial comparison of clinical outcomes after arthroscopic capsular release for refractory frozen shoulder with and without diabetes. Arthroscopy 2016;32:1515-20. Crossref

25. Rizvi SM, Harisha AJ, Lam PH, Murrell GAC. Factors affecting the outcomes of arthroscopic capsular release for idiopathic adhesive capsulitis. Orthop J Sports Med 2019; 7:2325967119867621. Crossref

26. Yıldız F, Sarı A, Pulatkan A, Uçan V, Kochai A, Bilsel K. Effect of nonoperative concomitant intraarticular pathologies on the outcome of arthroscopic capsular release for adhesive capsulitis of the shoulder. Acta Orthop Traumatol Turc 2018;52:2458. Crossref

27. Boutefnouchet T, Jordan R, Bhabra G, Modi C, Saithna A. Comparison of outcomes following arthroscopic capsular release for idiopathic, diabetic and secondary shoulder adhesive capsulitis: A systematic review. Orthop Traumatol Surg Res 2019;105:839-46. Crossref

28. Grant JA, Schroeder N, Miller BS, Carpenter JE. Comparison of manipulation and arthroscopic capsular release for adhesive capsulitis: a systematic review. J Shoulder Elbow Surg 2013;22:1135-45. Crossref

29. Gallacher S, Beazley JC, Evans J, Anaspure R, Silver D, Redfern A, et al. A randomized controlled trial of arthroscopic capsular release versus hydrodilatation in the treatment of primary frozen shoulder. J Shoulder Elbow Surg 2018;27:1401-6. Crossref 